\title{
RODOLFO LENZ, 150 AÑOS EN DISPUTA CON EL IMPERIO DE LA LENGUA ${ }^{1}$
}

\author{
Rodolfo Lenz, 150 years in dispute with the empire of language
}

\author{
Vicente Bernaschina *
}

\section{RESUMEN}

Considerando el sesquicentenario del nacimiento de Rodolfo Lenz, el presente artículo invita a una revisión de su obra con dos objetivos principales: por un lado, observar algunas de las tensiones y rechazos que provoca su obra frente al establecimiento e institucionalización de la filología hispánica a inicios del siglo $\mathrm{XX}$ y, por el otro, destacar contrastivamente al modelo hispanista, aspectos de sus análisis sociolingüísticos y psicolingüísticos que son de fundamental importancia tanto para la historia como para la actualidad de la crítica literaria en América Latina.

Palabras clave: Rodolfo Lenz, filología hispánica, sociolingüística, crítica literaria, América Latina.

\footnotetext{
* Instituto de Romanística, Universität Potsdam. Potsdam, Alemania. Correo electrónico: vicentebernaschina@gmail.com

${ }^{1}$ El presente texto surgió a partir del impulso de Sergio Ugalde Quintana, a quien agradezco sus constantes inquisiciones sobre la labor de Rodolfo Lenz en Chile y su generosa colaboración; una versión más breve del mismo fue presentada en el simposio Politik der Kritik. Ideologie, Geschichte, Akteure der Literaturkritik, celebrado los días 11 y 12 de junio de 2013 en la Universidad de Potsdam. Aprovecho también de agradecer la lectura atenta y los pertinentes comentarios del revisor externo de la revista.
} 


\begin{abstract}
Considering the 150th aniversary of Rodolfo Lenz's birthday, this article proposes a revision of his works and follows two main goals: on the one hand, to observe some of the tensions and rejections his works aroused in the face of the institutionalization of Spanish Philology at the first decades of the XXth century; on the other hand, to contrast this hispanist model with some aspects of Lenz's sociolinguistics and psycholinguistics analyses, whose importance are still fundamental for the history of literary criticism in Latin America as well as for its present.
\end{abstract}

Keywords: Rodolfo Lenz, spanish philology, sociolinguistics, literary criticism, latin America.

"En materia orto-gráfica rige la misma ley histórica que en asuntos de orto-doxía” (Omer Emeth 6).

A la memoria y la obra de Rodolfo Lenz en el sesquicentenario de su nacimiento.

Invoco la memoria y la obra de Rodolfo Lenz con la esperanza de resarcir un poco la injusticia que todavía padece y con el fin de traer a escena algunas de sus propuestas para enriquecer nuestras reflexiones críticas sobre las lenguas, las literaturas y las culturas. Si bien su figura es recordada periódicamente en Chile, la preparación de una antología crítica de su obra no parece asomar en el horizonte y su campo de acción está reducido principalmente al folclore y la cultura mapuche. ${ }^{2} \mathrm{Mi}$ sospecha es que sobre la obra de Lenz pesan aún con demasiada potencia los juicios emitidos por la filología hispánica moderna, es decir, aquella practicada y fomentada durante la primera mitad del siglo XX por Ramón Menéndez Pidal, Américo Castro y Amado Alonso, entre muchos otros, desde la sección de filología del Centro de Estudios Históricos de Madrid e instituciones de investigación asociadas.

\footnotetext{
${ }^{2}$ Rudolph Lenz Danziger nació en Halle el 10 de septiembre de 1863, se doctoró en la Universidad de Bonn con un estudio Acerca de la fisiología e historia de las palatales (Summa cum laude) y luego de enseñar idiomas en Gymnasien de Köln y Wolffenbüttel, llegó a Chile en 1890 a instancias de la fundación del nuevo Instituto Pedagógico (29 de abril de 1989), para impartir clases de lenguas extranjeras, en específico francés, inglés e italiano. En 1903, Lenz se hizo cargo de la cátedra de gramática castellana del Instituto Pedagógico de la Universidad de Chile. En 1919, fue invitado por el Consejo de Instrucción Pública a formar parte de la comisión que tenía a su cargo la reforma de la gramática castellana para los estudios secundarios del país. Al año siguiente, al fallecer el Dr. Federico Hanssen, asumió la cátedra de gramática histórica castellana en el mismo Instituto. En 1931, fue recibido como miembro de la Facultad de Filosofía y Ciencias de la Universidad de Chile. Más datos sobre su vida y el impacto de su obra en los campos de la educación, lingüística, lexicografía, folclore, lengua y literatura mapuches pueden consultarse en Escudero (1963), Bernales (1988), Carrasco (1988), Contreras (1989), Sánchez (1992), Rabanales (2002), Salinas (2011). En específico, respecto de las dificultades que enfrentó, producto del nacionalismo y el rechazo que produjo la llegada de un contingente de profesores alemanes al Instituto Pedagógico, ver de la Barra (1899), Letelier (1940) y Sanhueza (2011). Una bibliografía de su obra puede encontrarse en Escudero.
} 
Me propongo, entonces, dos objetivos: el primero, mostrar brevemente la manera en que, durante el período de formación y estabilización de la filología hispánica moderna, el proyecto lingüístico de Lenz fue relegado al campo de la "acientificidad" o, en el mejor de los casos, al de la curiosidad étnica por aquellas tres figuras de la filología, con el fin de fortalecer una premisa fundamental: a saber, la unidad esencial del español, desde la cual se desprende una norma culta o literaria que no sólo es garante de la comunidad espiritual y cultural entre América y la Península, sino además guía para los objetivos y metodologías de las ciencias del lenguaje vinculadas al castellano. El segundo objetivo, y que no es menos importante, es la exposición de algunas premisas centrales del proyecto filológicoetnológico de Lenz, puesto que sus dimensiones psico- y sociolingüísticas tienden hacia ámbitos de exploración que desestabilizan la hegemonía absoluta de la lengua castellana en su unidad esencial. Estoy seguro que una contraposición de éste modelo con el hispánico hegemónico nos hará ver lo imprescindible que es recuperar críticamente la obra de Rodolfo Lenz, no sólo para la fonética, la lingüística o el folclore, sino para los estudios literarios y la crítica actuales.

En las últimas décadas, la filología española moderna ha sido objeto de investigaciones críticas que han puesto en evidencia para la academia, algo que siempre sospechamos desde la crítica: me refiero al carácter ideológico de sus fines y de su formación disciplinar. ${ }^{3}$ Si bien -es necesario advertirlo-, resulta riesgoso reducir las diversas labores científicas practicadas durante la primera mitad del siglo XX por muchos humanistas y filólogos, provenientes de diversas naciones y con distintas inclinaciones políticas, a la idea de una filología hispánica moderna homogénea, en lo que concierne a la determinación de un campo de estudios coherente y al establecimiento de objetivos y metodologías acordes con él, se perciben en Ramón Menéndez Pidal, Amado Alonso y Américo Castro una orquestación de ideas y argumentos pan-hispánicos que revelan un fuerte carácter ideológico. Que los derroteros vitales y científicos de cada uno de ellos los llevaran por caminos diferentes -el primero concentrado en el Romancero y la tradición, el segundo en la estilística y el tercero en la historia de la España de las tres culturas-, es un hecho relacionado íntimamente con las transformaciones que se produjeron, por un lado, con el auge del paradigma estructural en las ciencias humanas y, por el otro, con las experiencias traumáticas de la Guerra Civil española, la Segunda Guerra Mundial y las décadas

${ }^{3}$ Para la larga historia de la pugna entre la crítica latinoamericana y la filología hispánica, recordemos, a modo de ejemplo, el temprano libro de Fernando Ortíz, La reconquista de América, publicado hacia 1910. 
de exilio bajo el franquismo. Sin embargo, esto no elide la existencia de una fase de consolidación de la filología hispánica en la que Menéndez Pidal, Alonso y Castro trabajaron conjuntamente, persiguiendo objetivos pan-hispánicos similares.

Fundamental para esta fase de consolidación resultan el desastre colonial de 1898 y la agudización de los nacionalismos periféricos en la península y de las querellas independentistas en América y el Caribe durante las primeras décadas del siglo XX. Las élites intelectuales y políticas españolas, sumergidas en una profunda introspección sobre la sociedad civil, la cohesión nacional, el funcionamiento de las instituciones y las características espirituales que podrían interpretarse como las causas de aquella crisis, habían asumido la tarea de iniciar "un proceso de modernización institucional, económica, social, e intelectual capaz de acortar distancias con Europa y de integrar a España en las pautas de las demás naciones Europeas" (Elizalde, 2000: 202). Para ello, España debía presentarse ante las demás potencias imperiales como una nación fuerte y moderna, que si bien ya no poseía territorios coloniales oceánicos, seguía detentando las fuerzas espirituales que habían sido el germen de uno de los imperios culturales más extensos a nivel global.

Dentro de este contexto, la misión que asumió la filología fue la recomposición de la comunidad espiritual y cultural que compartían América y la Península, dentro de la cual, por supuesto, la España castellana ocupaba el sitial hegemónico por origen y genealogía. José del Valle, por ejemplo, al estudiar el período de regeneración nacional y sus utopías lingüísticas, ha insistido en el perfil eminentemente nacionalista -imperial sin más, diría yo- que guiaba los esfuerzos de Ramón Menéndez Pidal en su carrera por "contrarrestar el sentimiento antiespañol que pudiera existir en las antiguas colonias y asegurar la lealtad de la élite al proyecto de construcción de una comunidad hispánica moderna en la que se reservara un papel central a España" (Valle, 2004: 111). Un proyecto político, entonces, que se sirvió, por una parte, del poder retórico de la ciencia con el fin de entregar una imagen icónica del castellano, desde sus orígenes y a lo largo de toda su historia, que lo retratara como una lengua civilizadora en esencia; ${ }^{4}$

\footnotetext{
${ }^{4}$ Según del Valle y Stheeman, el nacionalismo cultural, en sus esfuerzos por prevalecer, genera inevitablemente ideologías lingüísticas que utilizan principalmente dos procedimientos retóricos para legitimarse: ocultamiento e iconización. El primer procedimiento redunda en una simplificación del campo sociolingüístico, invisibilizando a ciertas personas o actividades, mientras que el segundo, implica una transformación de la relación semiótica entre rasgos lingüísticos o variedades lingüísticas con las imágenes sociales a las que están vinculadas, lo que hace que ciertos rasgos lingüísticos aparenten ser representaciones de la esencia o naturaleza inherente de un grupo social (Valle y Stheeman, 2004: 32).
} 
y que, por el otro, supo aprovechar el poder simbólico otorgado por múltiples discípulos y colaboradores internacionales, revistas especializadas e instituciones de investigación y educación como lo fueron el Centro de Estudios Históricos de Madrid, la American Association of Teachers of Spanish y el Instituto de Filología de la Universidad de Buenos Aires; este último caso estudiado recientemente por Guillermo Toscano y Fernando Degiovanni, quienes demuestran, estudiando los años de formación de dicho Instituto, así como la famosa polémica entre Jorge Luis Borges y Américo Castro respecto de la lengua rioplatense, los modos en que el proyecto filológico español logró imponer sus intereses sobre la unidad de la lengua ante los estudios sobre fenómenos de variación.

Este desenmascaramiento ideológico, si bien fundamental para la comprensión y escritura de la historia de la filología y la crítica en América Latina, pierde de vista el desarrollo de otros programas o proyectos que, por contrarios a las premisas hispanistas, se interpretan como reacciones anticoloniales y de igual signo nacionalista. Es el peligro de la polémica: en este caso, por mantener la posición central de la filología hispánica en el ojo del huracán, América Latina parece un vasto y confuso territorio cultural, cruzado principalmente por intereses pro- y antiespañoles, obsesionado a veces con su autoctonismo, flotando a merced de las propuestas científicas, filológicas o críticas europeas. En este punto es que una mirada atenta a la obra de Rodolfo Lenz y al rechazo que provocó en el proyecto hispano resulta reveladora para cambiar el enfoque.

En 1939, tiempos en los que dirigía el Instituto de Filología de Buenos Aires, Amado Alonso publicó en la Revista de Filología Hispánica de esa misma institución, un extenso artículo titulado "Examen de la teoría indigenista de Rodolfo Lenz", que posteriormente fuera incluido en sus Estudios filológicos: temas hispanoamericanos publicado en Madrid por editorial Gredos. Este artículo, como lo declara Alonso, propone un análisis sistemático de todos los rasgos que se organizaban en torno a la polémica tesis araucanista de Lenz, a saber, "que el español de Chile (es decir la pronunciación del bajo pueblo) es, principalmente, español con sonidos araucanos" (Lenz, 1940: 249). Con miras a la próxima aparición de los estudios fonéticos vinculados a esta tesis - por primera vez todos juntos y en castellano y que apareció finalmente en 1940- en una traducción comentada por él mismo (Alonso) y Raimundo Lida y que correspondía al sexto tomo de 
la "Biblioteca de Dialectología Hispanoamericana" del Instituto de Filología de Buenos Aires, Alonso creía fundamental un examen sistemático y exhaustivo de aquellos primeros estudios de Lenz: había que precaver a los lectores, quienes acaso llevados por la "autoridad técnica" de "un hombre de ciencia" como Lenz y por el "renovado prestigio que las teorías del sustrato étnico-lingüístico han cobrado entre los lingüistas en los últimos años” (Alonso, 1961: 270-271), se dejarían arrastrar por estas ideas y podrían convencerse de la posibilidad de algún indigenismo o de quiméricos paralelismos lingüísticos-culturales. Había que ser claro y decirlo con todas sus letras: los trabajos de Lenz, por muy científicos que parecieran, seguían "una tesis sensacionalista preconcebida, con métodos deficientes que las afirmaciones hiperbólicas no logran disimular, y sin noticias de las formas vulgares y dialectales del español de la Península y de América, lo cual le hacía tomar por sorprendente desarrollo chileno y antihispánico lo que es general" (Alonso, 1961: 281).

Sin entrar a discutir los argumentos fonéticos de Alonso-que probablemente bajo su lógica y sus leyes sean coherentes- ni los de carácter cultural e histórico -en los cuales sí hay mucho de simplificación y malos entendidos-, me interesa más bien preguntarme ¿por qué esta insistencia sobre la antigua tesis de Lenz?

Ya en 1905, en nota al pie en el párrafo 35 de su Manual de gramática histórica española, Menéndez Pidal, al referirse a las "Consonantes españolas", rechazaba la tesis "araucanista" de Lenz, indicando la extensión geográfica de algunos fenómenos fonéticos que éste consideraba especiales de Chile (Menéndez Pidal, 1905: 66). Comentario que también reiteraría después en su conocido ensayo "La lengua espańola" de 1918, al asegurar que la influencia de las lenguas indígenas sobre la fonética del español es despreciable: "Como un rasgo de los más seguros se ha atribuído al araucano la $r$ fricativa chilena, y el grupo $t r$ africado, semejante a una $c h$; pero matices de estos mismos sonidos se hallan en toda la América española, muy lejos de la influencia araucana, y hasta en las España misma" (Menéndez Pidal, 1918: 4). Por su parte, Américo Castro, había aprovechado las traducciones comentadas que hizo del estudio de Max Leopold Wagner "El español de América y el latín vulgar" (1924) y de la Introducción a la lingüistica románica (1926) de Wilhelm Meyer-Lübke para desestimar todo posible influjo fonético que el mapuche pudiera tener sobre el español de Chile, 
remitiendo tanto a los estudios de Menéndez Pidal como a uno de los primeros estudios con los que Amado Alonso se estrenaría en la fonética: "El grupo 'tr' en España y América” $(1925)^{5}$. En éste temprano trabajo, Alonso asumía el desafío de estudiar exhaustivamente los grupos 'tr' y 'dr' en el habla de Navarra, Rioja y Aragón, para compararlos luego con los fonemas análogos registrados en Chile y Nuevo México (Alonso, 1925: 167). Comparación que para Alonso arrojaba resultados indiscutibles en relación con estos fonemas, para los cuales hasta ese momento, como lo hizo Lenz, se los había explicado como una evolución especial o paralela del español de América, debido a influencias geográficas, socioculturales y étnicas. Esa explicación, decía Alonso, es "imposible de aceptar, ya que el fonema en cuestión está ligado, aquende y allende el mar, a idénticas modalidades fonéticas y tendencias evolutivas que son sus determinantes" (Alonso, 1925: 172).

Ante esta cadena de rechazos y la constante apelación a fenómenos lingüísticos "españoles”, reitero la pregunta: ¿por qué esta insistencia sobre la antigua tesis de Lenz? Y pensando en la publicación en castellano de los textos juveniles de Lenz en la "Biblioteca de Dialectología Hispanoamericana” en 1940, ¿por qué Amado Alonso asumía la tarea de reeditar los estudios de Lenz, si en el fondo lo que se deseaba era acusarlos de falaces?

Aquí se podría aludir a aquella estrategia lingüístico-ideológica que del Valle y Stheeman denominan ocultamiento (vid. supra nota 4), aunque creo que en este caso las expresiones chivo expiatorio y castigo ejemplar resultan más adecuadas. A partir de los lugares específicos en los que Menéndez Pidal y Américo Castro realizan sus comentarios sobre la obra de Lenz y a partir de las aseveraciones de Alonso en sus trabajos de 1925 y 1939, se aprecia una clara intención de evitar que, a partir de las tesis de Lenz, se produjeran polémicas que amenazaran la estabilidad hegemónica del español, sabiendo que las herencias indígenas y criollas conformaban un caldo de cultivo de ideas fragmentacionistas en las naciones americanas. Un peligro latente que ya se había manifestado a inicios del siglo XX en los diversos intentos por definir en varios países un "idioma patrio" divergente del castellano, tal como sucedió en Argentina a partir del libro de Luciano Abeille, El idioma nacional de los argentinos (1900), o en Chile en torno a la conferencia de

\footnotetext{
${ }^{5}$ Los comentarios en nota al pie de Américo Castro se encuentran en la página 61 del texto de Max Leopold Wagner, "El español de América y el latín vulgar" y adjuntos al párrafo 231 de la Introducción a la lingüística románica de Wilhelm Meyer-Lübke. Ambos trabajos citados en la bibliografía.
} 
Julio Saavedra, Nuestro idioma patrio (1907), así como en las polémicas en torno al supuesto andalucismo del español de América, como lo constatan las numerosas citas a los trabajos de Lenz por parte de Pedro Henríquez Ureńa y Max Leopold Wagner, iniciadores y protagonistas de aquellos debates en los años ' $20 .{ }^{6}$

Pero eso no era todo. Además, existía el peligro de que muchos investigadores, aparte de recurrir a las tesis juveniles de Lenz creyéndolas correctas, se adentraran, por curiosidad o sensacionalismo, en su obra de madurez, la cual constituía definitivamente un modelo contrario al hispánico y sus pretensiones sobre la unidad de la lengua espańola. Había que ir, entonces, no sólo a refutar el impulso originario de la carrera científica de Lenz, sino también los principios epistemológicos que fundaban el armazón de su proyecto filológico. Tarea que Américo Castro emprendió personalmente, de cara a los colegas y estudiantes de Rodolfo Lenz, en una serie de conferencias dictadas en el Instituto Pedagógico de la Universidad de Chile a fines de 1923. Pero antes de eso, ¿cuáles eran las ideas principales de los estudios filológicos y prácticas docentes de Rodolfo Lenz? ¿Cuáles sus riesgos para la filología española?

El enfoque teórico de Lenz considera que el lenguaje es un fenómeno sicofísico del ser humano en general y por ello, la clave para la comprensión antropológica de las vidas y culturas humanas. Al mismo tiempo, el lenguaje "es también, casi diría en primer lugar, un fenómeno social de cada nación y como tal toda explicación de lo existente debe fundarse en la historia del pasado" (Lenz, 1912a: 38). Premisa que, por su simultánea dimensión sicológica, social e histórica, no podía avenirse con las premisas de la filología hispánica referentes a una historia absolutamente castellana ni al ideal rector de la lengua; ambos factores que determinarían para cada hablante "lo que es 'natural' en su lengua y lo que 'debe ser' su lengua” (Alonso, 1961: 278), como lo formulaba Amado Alonso; y que según Menéndez Pidal, se percibía siempre en la lengua culta española que, dilatada sobre los círculos menores y sedentarios de los dialectos regionales, "se difunde dondequiera que llega la actividad de los hombres de acción o el brillo de las inteligencias más eficaces que se sirven del mismo idioma" (Menéndez Pidal, 1918: 2).

${ }^{6}$ Ver los textos de Pedro Henríquez Ureńa y Max Leopold Wagner citados en la bibliografía. Además, para una discusión acerca de los condicionantes ideológicos y culturales de esta polémica, ver del Valle "Andalucismo" (1998). 
Lenz, además, sospechaba que estas ideas no eran más que una reformulación de las apolilladas ideas sobre la corrección idiomática. Para Lenz, la gramática no era, por ningún motivo, un arte dirigido a la normatividad, como todavía se aseguraba al seguir la gramática de Andrés Bello o de la Real Academia Española (Lenz, 1920: 364-367), sino una teoría de un idioma, cuyo fin era organizar y hacer comprensible las características lógicas y sicológicas propias de ese idioma (Lenz, 1912a: 15). Científicamente hablando, no puede existir una forma considerada correcta absoluta y menos vinculada a un grupo específico, por ejemplo, la gente "culta". "El profesor", dice Lenz al hablar de las posibilidades pedagógicas de la gramática, "no debe olvidar que todo el lenguaje efectivamente usado por una comunidad étnica dentro de su esfera tiene su derecho a existir y es correcto” (Lenz, 1912a: 35).

Por lo mismo, en lo que respecta a la construcción histórica de una norma culta o literaria, para él, el asunto es evidentemente convencional y político. A diferencia del modelo de Menéndez Pidal sobre la primacía general de un espíritu hispano rector de la lengua culta, Lenz asegura que los dialectos vulgares "no son de ninguna manera corrupciones de las lenguas literarias, sino que, al contrario, las lenguas literarias representan el estado anormal de un cultivo artificial" (Lenz, 1912a: 15). O como lo advierte en la introducción a su Diccionario etimológico de las voces chilenas derivadas de lenguas indígenas americanas utilizando términos más legos: "En materia de lenguaje, tanto como en las demás esferas de la vida social [...] la voluntad de la mayoría es la norma, la ley. El uso del término medio de la gente que maneja el idioma literario constituye la norma del lenguaje" (Lenz, [1905-1910] 1977: 12).

Fascinante resulta, a partir de esta dimensión política, el modelo con el que Lenz propone describir el funcionamiento social y las dinámicas de variación y estabilización de una lengua trasplantada, sobre todo porque este fenómeno representa su constitución histórica desde una dimensión social: “Trasplantada a los vastos territorios de la América la lengua de los conquistadores castellanos, tuvo que amoldarse a la naturaleza antes desconocida del nuevo mundo, tuvo que adaptarse a otro sistema de vida, con alimentación y habitación distintas de las antiguas españolas" (Lenz, 1912b: 4). 
Para Lenz, como se aprecia en esta cita, la lengua está vinculada a los sistemas de vida de los hablantes, al medio en que viven y a partir del cual crean su cultura; y, por lo tanto, su comportamiento "natural" es su tendencia a variar, más aún cuando la distancia de su centro irradiador, sumada a las nuevas condiciones sociales y naturales del medio en el que se ha insertado, fomenta su fragmentación en provincialismos y dialectos (Lenz, [1905-1910] 1977: 10).

Ahora bien, concede Lenz, esta tendencia puede alterarse cuando en una comarca se forma un gobierno lo suficientemente fuerte para establecer dominio político y cultural, imponiendo un modo de hablar sostenido por el estatus social que implica el uso de la lengua hegemónica. Lenz lo expresa del siguiente modo:

\footnotetext{
"Este estado natural se altera cuando en una comarca se forma un Gobierno fuerte que principia a dominar en regiones suficientemente apartadas para que el lenguaje sea distinto del que se usa en el centro gubernativo. La administración de las provincias estará en manos de personas procedentes el centro; a su modo de hablar se acomodarán los provincianos que quieren significar algo en la corte central; leyes y ordenanzas se impondrán en el dialecto central; y como la comunicación a larga distancia se hace por carta, habrá que fijar por la escritura ese lenguaje central. En el centro de la actividad política se juntarán también los poetas, nacerá la literatura, y esta literatura será leída por los provincianos y les servirá de modelo. Así se han formado sobre base lingüística natural, pero por razones históricas de política, las que solemos llamar lenguas literarias"(Lenz, [1905-1910] 1977: 11).
}

La oración que concluye el párrafo es decidora. La lengua literaria que se instituye como norma y modelo de la lengua $-\mathrm{y}$ para Lenz es fundamental advertirlo-, en cuanto producción artística, no expresa jamás los vastos alcances de la lengua general, que está compuesta por distintas capas sociales, distintos usos y, en algunos casos, distintas lenguas. Si bien, dice Lenz utilizando una metáfora topológica social, "hacia arriba prevalece la lengua escrita" con sus formas y usos especiales, "hacia abajo prevalece la comunicación oral; la esfera de la vida doméstica y todas sus múltiples relaciones con la vida del individuo en cuanto a habitación, vestimenta, alimentación, con los artesanos y el comercio al menudeo que satisfacen necesidades diarias" (Lenz, [1905-1910] 1977: 12). Y aún más abajo, dónde los límites se difuminan en la vida cotidiana, se produciría "el continuo contacto con gente de poca o ninguna educación escolar" que obliga a usar términos dialectales (Lenz, [1905-1910] 1977: 13). 
De esta exposición, se desprende que la noción que Lenz maneja acerca del funcionamiento y desarrollo de la lengua reconoce al menos tres esferas sociolingüísticas diferentes -lenguaje literario, lenguaje nacional y lenguaje familiar, las denomina (Lenz, [1905-1910] 1977: 13)-, cada cual con su propio sistema expresivo, determinado por sus actividades diarias, aunque no por ello desvinculadas en sus procesos dinámicos. La "lengua general" existe, entonces, en constante variación y adquiere su sentido no desde una esencia inmutable que la antecede, sino precisamente a partir de las interacciones de todos estos grupos. Y si la lengua literaria adquiere el puesto de sistema rector, esto lo hace, repito, "por razones históricas de política”, lo que tampoco quiere decir que no esté sujeta a variaciones determinadas por los comportamientos sociales.

Significativo es que Menéndez Pidal, al menos como lo expone en una conferencia con fines divulgativos de 1944 titulada "La unidad del idioma", reconozca también la existencia de tres esferas - habla culta o literaria, habla popular y habla vulgar-, pero con un funcionamiento diferente en el que la primacía del habla literaria responde a un proceso natural y esencial de interacción dialéctica entre ésta, como eje rector, y las hablas populares regionales. Menéndez Pidal, al referirse al habla y no a la lengua, realiza una salvedad metodológica con la que da a entender que en su uso, un idioma experimenta siempre desviaciones con respecto al sistema ideal desde el que se desprende. Sin embargo, dichas desviaciones en la superficie tienden siempre a reorganizarse en torno a la primacía del sistema.

Así, el desarrollo evolutivo de la lengua, se da entre el habla literaria y la popular en la forma de "dos líneas ondulantes que caminan a la par y en la misma dirección” y cuya unidad está dada por el peso de la tradición (Menéndez Pidal, [1944] 1947: 187). ${ }^{7}$ Es decir, la manifestación histórica de "la idea de la lengua" de la que hablaba Alonso y que Menéndez Pidal resuelve aforísticamente: "la lengua está en variedad continua y en permanencia esencial" (Menéndez Pidal, [1944] 1947: 196). Lo que en términos ideológicos significa, como lo aclara del Valle, la existencia de una "visión superior (de un modelo civilizador) ofrecido por Castilla primero y por España más tarde a la comunidad hispánica en su conjunto" (Valle, 2004: 119).

\footnotetext{
${ }^{7}$ La lengua vulgar, que como dice del Valle (2004: 125), es la que presenta los mayores peligros para la unidad de la lengua, desaparece rápidamente del esquema, puesto que al carecer de tradición, carece de gravedad sustancial.
} 
Es importante notar que este plan, que se vislumbra con claridad en Menéndez Pidal ya en el ensayo "La lengua española" de 1918 si no antes, también se halla presente en las siete conferencias dictadas en Chile a fines de 1923 por Américo Castro, cuando ocupaba el cargo de director del Instituto de Filología de Buenos Aires y era el representante de la moderna filología española en América del sur. ${ }^{8}$

De estas conferencias, destinadas a los profesores y estudiantes de castellano del Instituto Pedagógico y que marcan un recorrido que por sí sólo es ya decidor -desde el origen del castellano en los siglos IX y X, pasando por el humanismo hasta llegar a Cervantes y Lope de Vega-, me quiero concentrar brevemente en la conferencia con la que Castro concluyó el ciclo, dedicada a la "Metodología y enseñanza de la lengua y literatura españolas". Puesto que en ésta, Castro se plantó frente a los colegas y estudiantes de Lenz, quienes por supuesto estaban al tanto de las polémicas investigaciones de éste último, y junto con una fuerte promoción de los métodos y perspectivas de la filología española, se dedicó a un indirecto, aunque insistente desmontaje de las premisas lingüísticas sostenidas por Lenz.

Ahora bien, hay que reconocerlo, la primera provocación había surgido conscientemente de la pluma de Lenz. Hacia 1916, como lo cuenta Lenz en una carta a Robert Lehmann-Nitsche fechada el 23 de septiembre de 1917, Menéndez Pidal lo había invitado a publicar un estudio sobre gramática castellana en la Revista de Filología Española. Sin embargo, a final de cuentas, el texto creció tanto, que Lenz estaba seguro de que no se lo aceptarían. Para su sorpresa, Menéndez Pidal cambió la oferta y sugirió no publicar un estudio, sino un manual para estudiantes universitarios, auspiciado por la Junta para Ampliación de Estudios e Investigaciones Científicas. Así, Lenz se puso manos a la obra y en 1920 entregó a la imprenta del Centro de Estudios Históricos de Madrid su estudio La oración y sus partes; libro polémico no sólo por la complejidad del enfoque y la cantidad de ejemplos de diversas lenguas (no necesariamente románicas), sino también por la provocación que significaban ya las primeras páginas para la filología española, en las que Lenz acusaba directamente de ignorante a todo aquel que pretendiera dar cuenta de la complejidad de las lenguas humanas a partir únicamente de una

\footnotetext{
${ }_{8}^{8}$ Las conferencias fueron publicadas en los Anales de la Universidad de Chile a lo largo del año de 1924 y hoy pueden consultarse en línea en: <http://www.anales.uchile.cl>.
} 
lengua indo-europea: "Esperar que sólo con el estudio de las lenguas europeas pudiéramos llegar a comprender la psicología del lenguaje humano, me parece tan razonable como si un naturalista quisiera fundar una fisiología botánica estudiando sólo las rosáceas" (Lenz, [1920] 1944: 31).?

Américo Castro, entonces, a sabiendas de que las tesis centrales de Lenz, en lo que respecta al funcionamiento social del lenguaje, se fundaban en su noción del lenguaje como manifestación sicofísica del ser humano, se arrimó a las propuestas más modernas de la lingüística estructural, declarando a la psicolingüística y la sociolingüística campos de investigación inciertos si es que no acientíficos.

Retóricamente dotado, era de esperar que Castro no iniciara su conferencia con un ataque directo al proyecto de Lenz, sino con una alabanza a la modernización de la lingüística en Chile y luego con una comparación de ésta con la española bajo la dirección de Menéndez Pidal (Castro, 1924: 838). En última instancia, las ideas de Lenz con respecto al rol científico y no normativo de la gramática las compartían todos aquellos que estuviesen al tanto de los últimos avances en los estudios lingüísticos (Castro, 1924: 839). Sin embargo, establecidos aquellos principios fundamentales, Castro comienza a introducir divergencias y a cuestionar abiertamente aquellos estudios que vinculan pensamiento y lenguaje, puesto que, según él, "no hay terreno más escurridizo hoy que éste de la psicología" (Castro, 1924: 845). Así, luego de citar algunos ejemplos de la lingüística francesa y sus dudas ante los estudios de la psique humana, establece la siguiente propuesta:

"[Y]o creo fundamental en cuanto al lenguaje es estudiarlo separadamente del pensamiento y de la realidad. [...] El lenguaje, se ha dicho con razón, no es lógico, es sicológico, pero hay que añadir: el lenguaje, fundamentalmente, es lenguaje. Es como una encrucijada; hay en él una interferencia del mundo del pensar, del mundo íntimo, y del mundo real; pero no indica esto que el lenguaje, por sí mismo, carezca de sustantividad. Tal como la encrucijada, es algo distinto de los caminos que en su terreno se cruzan. El lenguaje debe estudiarse como algo sustantivo. [...] El lenguaje vive autonómicamente entre el pensar, el sentir y la realidad" (Castro, 1924: 845-46).

\footnotetext{
${ }^{9}$ La conciencia de esta provocación se puede leer en la misma carta que envió Rodolfo Lenz el 23 de septiembre de 1917 a Robert Lehmann-Nitsche, en la que le confiesa el carácter propagandístico que tiene este libro de la lingüística y psicología étnica alemana, además de una perspectiva comparatista amplia en la cual también tiene cabida una gran cantidad de mapuche. Nachlass (legado) de Robert Lehmann-Nitsche, Korrespondenzen: Briefe von Rodolfo Lenz an Robert LehmannNitsche, Ibero-Amerikanisches Institut, Preußische Kulturbesitz, Signatur: N-0070 b 420.
} 
¿Y qué es aquello que substancia a la lengua más allá o más acá del pensar, el sentir y la realidad? Por supuesto que no "las manifestaciones anárquicas y selváticas del hablar", "esa floración espontánea del lenguaje desprovisto de cultura" (Castro, 1924: 844), sino el lenguaje culto y la literatura, herederos de las tradiciones universales y que otorgan "el verdadero sentido de las palabras" (Castro, 1924: 842). Por lo mismo, en lo que respecta a la formación profesional de los profesores de castellano, "la cultura universitaria debe ser para el maestro, la cultura latina para el profesor de una lengua latina como la nuestra" (Castro, 1924: 842). Lengua latina y cultura latina, que "a lo largo de la historia de la literatura española de los siglos XIV a XIX", está plagada de "hechos interesantísimos para la formación del espíritu moderno" (Castro, 1924: 852).

Observando reacciones directas o indirectas de la crítica literaria y de la filología durante los años '20 y '30 ante los problemas lingüístico-culturales aludidos por la obra de Lenz, queda en evidencia que este llamado a la tradición hispana, latina y romana, al espíritu moderno de una determinada historia que debía acercar a América y a Espańa conjuntamente a la cultura de Occidente, realizado por personalidades reconocidas internacionalmente y apoyadas por instituciones como el Centro de Estudios Históricos de Madrid y el Instituto de Filología de Buenos Aires, tuvo resonancias mucho más atractivas para todos aquellos profesores y estudiantes, que se dejaban deslumbrar, aunque fuera tensamente, con la promesa de poder reclamar algún día próximo aquella larga tradición para sí.

Para los intelectuales de una crítica latinoamericana emergente como Pedro Henríquez Ureña, quien había leído a Lenz y que en Buenos Aires trabajó junto a Américo Castro y Amado Alonso, o como Mariano Picón Salas, quien estudió pedagogía en Historia en el Instituto Pedagógico de la Universidad de Chile y que por lo tanto no debía desconocer las ideas de Lenz, el problema de la integración viva de las tradiciones indias y populares a la construcción de una cultura latinoamericana y no como meras herencias remotas, no dejó de ser extremadamente tenso. Para ambos, las lenguas y tradiciones indias representan un horizonte de difícil asimilación; en la medida en que no pertenecen a Occidente, con ellas se corre siempre el riesgo de impostar la voz, de abandonar el curso de la 
historia y del progreso, de caer en autoctonistas quimeras. ${ }^{10}$

En el ámbito académico, por otra parte, son muy elocuentes los semitonos y reparos que menciona Rodolfo Oroz en su "Discurso en la recepción del Dr. Rodolfo Lenz, como Miembro Académico de la Facultad de Filosofía y Ciencias de la Educación", al tener que aludir, entre tantos elogios, aquellos trabajos de juventud que enunciaban las famosas tesis araucanistas: "Y aunque sea necesario hoy modificar la opinión del autor en varios puntos, en cuanto a la causa de los fenómenos estudiados, en el fondo, el trabajo de Lenz conserva su primitivo valor, gracias a las descripciones tan precisas de los diversos sonidos que caracterizan nuestro modo de hablar. Lenz, en aquel entonces, creyó que la pronunciación chilena, en lo esencial, era una mezcla del español con sonidos araucanos" (Oroz, 1933: 27).

En estas palabras de un discípulo y colega resuenan justamente aquellos aspectos ideológicos de la disciplina filológica que he referido a lo largo de este ensayo y que es fundamental reevaluar. Esta vez, eso sí, no bajo el signo de una tesis sensacionalista, como lo dijo Alonso, de una errada opinión, como lo da a entender Oroz, o de una "idea falsa" que produjo curiosamente "efectos positivos", como lo escribió Ambrosio Rabanales hace una década (Rabanales, 2002: 168).

Acaso sea cierto que en un nivel general y sistemático no se pueda atribuir una evolución exclusivamente chileno-mapuche a ciertos fonemas de aparición general, pero eso tampoco quiere decir que la aparición de aquellas variantes se produjeran bajo el régimen absoluto de una ley de evolución fonética interna de la lengua y menos que no se puedan interpretar desde otra perspectiva. Precisamente ese punto de inflexión, ese plantear preguntas a contrapelo del imperio de la lengua, enfocándose en la interacción de prácticas lingüísticas y culturales heterogéneas, es uno de los motivos fundamentales del proyecto filológico de Lenz. Un proyecto que, como el mismo lo confesara en diversos estudios como La oración y sus partes o el Programa de la Sociedad de Folklore Chileno, no puede seccionarse en compartimentos estancos ni ordenarse bajo las premisas de la filología hispánica.

\footnotetext{
${ }^{10}$ Como manifestaciones paradigmáticas de esta tensión, basta recordar el apartado "El problema del idioma” de los Seis ensayos en busca de nuestra expresión de Pedro Henríquez Ureña o algunos de los ensayos que Mariano Picón Salas escribiera mientras vivía en Chile: "Cautín, sur de Chile" y "América y el disparate" en Intuición de Chile o "Americanismo y autoctonismo" en Atenea.
} 
El lenguaje y las culturas humanas en general no pueden estudiarse sólo desde la perspectiva de una lengua indo-europea y las prácticas populares no pueden relegarse a un pasado muerto:

“[N]o cabe duda que el folklore de Chile como el de todas las repúblicas latino-americanas ha de ser de los más interesantes. No sólo se trata de averiguar en qué consiste lo particular del pueblo chileno, en qué se distingue de sus hermanos sud-americanos. Hay que investigar cuáles elementos fueron traídos de la patria común, Espańa; cómo se desarrollaron y diferenciaron en cada región; qué elementos indígenas se aceptaron en la gran mezcla de razas. [...] Naturalmente esta circunstancia también dificulta la cuestión, porque muchos puntos del folklore criollo dependerán del folklore de las tribus indias que entraron en mezcla con los espańoles. La cocina, la medicina casera, la industria casera de Chile, por ejemplo, están llenos de reminiscencias indias. ¿Cómo no ha de suceder lo mismo en el Perú, en México y más o menos en todas partes? Hay que estudiar el saber popular de todas las razas y de todos los restos de pueblos en América” (Lenz, 1909: 10-11).

Un estudio del lenguaje y de la cultura de estos alcances pone necesariamente en suspenso las tesis fundamentales de la gran historia de la lengua española. Como mencioné más arriba, estas prácticas materiales de la vida cotidiana son para Lenz una de las bases sobre las cuales se construye una lengua de uso que entra en contacto con otros usos provenientes de otras esferas sociales y por ello mismo resulta impensable que el sistema de la lengua identificado con la norma literaria sea capaz, en sí mismo, de eliminar o "corregir" dichas prácticas.

El sistema de la lengua o los principios fundamentales de su gramática pueden parecer inalterables, sin embargo, en el desarrollo social de una lengua en uso se producen variaciones que si bien se juzgan nimias, representan en el fondo cambios en los modos de pensar y de actuar de una sociedad frente a su medio y su historia particulares. Siguiendo con atención las propuestas de Lenz, resulta ostensible que el foco de atención y preocupaciones de los estudios filológicos cambia. El objetivo fundamental de una filología como ésta no es entonces la recomposición de la unidad esencial de una lengua, su sistema inmutable, sino precisamente su heterogeneidad: la indagación de aquellos puntos de articulación con formas de expresión provenientes de otros estratos sociales y comunidades étnicas, lo que implica una investigación radicalmente distinta, en la que es imprescindible aceptar una historia de la lengua diferente y desear contarla en sus propios términos. 
Por lo mismo, hacia el final de su conferencia titulada ¿Para qué estudiamos gramática?, Rodolfo Lenz invitaba a profesores y alumnos a "fomentar el cultivo de la verdadera literatura popular hispano-americana al lado de la literatura artística de la lengua de Cervantes" en cuanto "tarea recomendable a la enseñanza pública de las Repúblicas de América” (Lenz, 1912a: 39). Y por lo mismo, el insistente rechazo de sus tesis de juventud por parte de la filología hispánica.

\section{REFERENCIAS}

Abeille, Luciano. El idioma nacional de los argentinos. Con una introducción por Louis Duvau. Paris: Lib. Émile Bouillon, 1900.

Alonso, Amado. "El grupo 'tr' en España y América”. Homenaje ofrecido a Menéndez Pidal: Miscelánea de estudios lingüisticos, literarios e históricos. Tomo II. Madrid: Librería y casa editorial Hernando, (1925): 167-191.

Alonso, Amado. Estudios lingüísticos: temas hispanoamericanos. 2a edición. Madrid: Editorial Gredos, 1961.

Bernales, Mario. "La actividad científica de Rodolfo Lenz en Chile”, Cuadernos de Lengua y Literatura (Homenaje al Dr. Rodolfo Lenz) 1 (1988): 9-19.

Carrasco, Hugo. "Rodolfo Lenz y el conocimiento y estudio de la etnoliteratura mapuche", Cuadernos de Lengua y Literatura (Homenaje al Dr. Rodolfo Lenz) 1 (1988): 35-64.

Castro, Américo. "Metodología de la enseñanza de la lengua i la literatura españolas", Anales de la Universidad de Chile 2 (segunda serie) (1924): 835-853.

Contreras, Constantino. "Lengua y folclore en la obra de Rodolfo Lenz", Estudios Filológicos 24 (1989): 39-53.

Degiovanni, Fernando y Toscano y García, Guillermo. "Las Alarmas de Don Américo Castro: Institucionalización filológica y autoridad disciplinaria”, Variaciones Borges 30 (2010): 3-41. 
"Disputas de origen: Américo Castro y la institucionalización de la filología en Argentina”, Nueva Revista de Filología Hispánica 58/1 (2010): 191-213.

De la Barra, Eduardo. El embrujamiento alemán: la vida nacional. Santiago de Chile: Establecimiento poligráfico Roma, 1899.

Elizalde Pérez-Grueso, María Dolores. "Balance del 98. Un punto de inflexión en la modernización de España o la desdramatización de una derrota", Historia y politica: Ideas, procesos y movimientos sociales 3 (2000): 175-206.

Escudero, Alfonso. "Rodolfo Lenz: 1863-1938”, Thesaurus 18 (1963): 445-484. Incluye bibliografía de la obra de Rodolfo Lenz.

Henríquez Ureña, Pedro. “Observaciones sobre el Español de América I”, Revista de Filología Española 8 (1921): 357-390.

. "El supuesto andalucismo de América”, Cuadernos del Instituto de Filología de Buenos Aires 2 (1925): 117-122.

Seis ensayos en busca de nuestra expresión. Buenos Aires: Babel, 1927.

-. "Observaciones sobre el Español de América II", Revista de Filología Española 17 (1930): 277-284.

- “Observaciones sobre el Español de América III", Revista de Filología Española 18 (1931): 120-148.

Lenz, Rodolfo. Estudios araucanos: materiales para el estudio de la lengua, la literatura i las costumbres de los indiosmapuche o araucanos. Diálogos en cuatro dialectos, cuentospopulares, narraciones históricas $i$ descriptivas $i$ cantos de los indios de Chile en lengua mapuche, con traducción literal castellana. Santiago de Chile: Imprenta Cervantes, 1895-1897.

Programa de la Sociedad de Folklore Chileno (Fundada en Santiago de Chile el 18 de julio de 1909). Santiago de Chile: Imprenta y encuadernación Lourdes, 1909. 
¿Para qué estudiamos gramática? Conferencia dada en la Universidad de Chile. Santiago de Chile: Imprenta Cervantes, 1912a.

. "Los elementos indios del castellano de Chile". Separata de las Actas del XVII Congreso de Americanistas. Buenos Aires: Imprenta de Coni Hermanos, $1912 \mathrm{~b}$.

- "La enseñanza del castellano i la reforma de la gramática. Memoria presentada al honorable Consejo de Instrucción Pública”, Anales de la Universidad de Chile 146 (primera serie) (1920): 343-395.

El español en Chile. Con trabajos de Andrés Bello y Rodolfo Oroz. Traducción, notas e introducción de Amado Alonso y Raimundo Lida. Buenos Aires: Instituto de Filología, Facultad de Filosofía y Letras de la Universidad de Buenos Aires, 1940.

La oración y sus partes. 4a edición. Santiago de Chile: Editorial Nascimento, [1920] 1944.

- Diccionario etimológico de las voces chilenas derivadas de lenguas indigenas americanas. 1905-1910. Edición facsimilar dirigida por Mario Ferreccio Podestá. Santiago de Chile: Universidad de Chile, Seminario de Filología Hispánica, 1977.

Letelier, Valentín. El Instituto Pedagógico. Prólogo de Roberto Munizaga A. Santiago de Chile: Publicaciones del Instituto Cultural Germano-Chileno, 1940.

Menéndez Pidal, Ramón. Manual elemental de gramática histórica española. 2a edición. Madrid: Victoriano Suarez, 1905.

. "La Lengua Española”, Hispania 1/1 (1918): 1-14.

. "La unidad del idioma". Castilla, la tradición, el idioma. Buenos Aires: Espasa-Calpe ([1944] 1947): 171-218. 
Meyer-Lübke, Wilhelm. Introducción a la lingüistica románica. Versión de la tercera edición alemana, con notas y adiciones por Américo Castro. Madrid: Hernando, 1926.

Oroz, Rodolfo. "Discurso en la recepción del Dr. Rodolfo Lenz, como Miembro Académico de la Facultad de Filosofía y Ciencias de la Educación”, Anales de la Universidad de Chile 10 (tercera serie) (1933): 25-30.

Ortíz, Fernando. La reconquista de América: reflexiones sobre el panhispanismo. París: Librería de Paul Ollendorf, 1910.

Picón Salas, Mariano. Intuición de Chile y otros ensayos en busca de una conciencia histórica. Santiago de Chile: Ercilla, 1935.

"Americanismo y autoctonismo". Prosas sin finalidad (1923-1944). Comp. Delia Picón-Salas de Morales. Caracas: Universidad Católica Andrés Bello, (2009): 240-243. Originalmente apareció en Atenea 38/144 (1937).

Rabanales, Ambrosio. "Rodolfo Lenz", Onomazein 7 (2002): 161-181.

Rojas Carrasco, Guillermo. Filología Chilena. Guía bibliográfica y crítica. Santiago de Chile: Ediciones de la Universidad de Chile, 1940.

Saavedra, Julio. Nuestro idioma patrio. Santiago de Chile: Edición La Revista Imprenta Universitaria, 1907.

Sánchez, Gilberto. "La contribución del Dr. Rodolfo Lenz al conocimiento de la lengua y cultura mapuches", Boletin de Filología de la Universidad de Chile 33 (1992): 273-299.

Sanhueza, Carlos. "El debate sobre 'el embrujamiento alemán' y el papel de la ciencia alemana hacia fines del siglo XIX en Chile". En Gloria Chicote y Barbara Göbel (eds.). Ideas viajeras y sus objetos. El intercambio cientifico entre Alemania y América austral. Madrid - Frankfurt am Main: Iberoamericana - Vervuert, (2011): 29-40. 
Salinas Campos, Maximiliano. "El amor en la poesía y canto popular de Chile. Un manuscrito inédito de Rodolfo Lenz: Die echte Volkspoesie. Dichtung und Musik der Frauen (1894)". En Gloria Chicote y Barbara Göbel (eds.). Ideas viajeras y sus objetos. El intercambio cientifico entre Alemania y América austral. Madrid - Frankfurt am Main: Iberoamericana - Vervuert, (2011): 305-319.

Toscano y García, Guillermo. "Materiales para la historia del Instituto de Filología de la Universidad de Buenos Aires (1920-1926)", Revista Internacional de Lingüistica Iberoamericana 7/1 (2009): 113-135.

Vaïsse, Emilio (Omer Emeth). Estudios criticos de literatura chilena. Tomo I. 2 vols. Santiago de Chile: Editorial Nascimento, 1940.

Valencia, Alba. "El legado de tres maestros: Lenz, Oroz y Rosales”, Revista de Lingüistica Teórica y Aplicada 31 (1993): 137-162.

Valle, José del. "Andalucismo, poligénesis y koineización: dialectología e ideología”, Hispanic Review 66/2 (1998): 131-149.

"Menéndez Pidal, la regeneración nacional y la utopía lingüística". La batalla del idioma: la intelectualidad hispánica ante la lengua. En José del Valle y Luis Gabriel Stheeman (eds.). Madrid - Frankfurt a. M.: Iberoamericana - Vervuert, (2004): 109-136.

Valle, José del y Stheeman, Luis-Gabriel. "Nacionalismo, hispanismo y cultura monoglósica". La batalla del idioma: la intelectualidad hispánica ante la lengua. En José del Valle y Luis Gabriel-Stheeman (eds.). Madrid Frankfurt a. M.: Iberoamericana - Vervuert, (2004): 15-33.

Wagner, Max Leopold. "Amerikanisch-Spanisch und Vulgärlatein", Zeitschrift für romanische Philologie 40 (1920): 286-312, 385-404.

Leopold Wagner, Max. "El Español de América y el latín vulgar”. Comentarios de Américo Castro y Pedro Henríquez Ureña, Cuadernos del Instituto de Filología de la Universidad de Buenos Aires 1/1 (1924): 43-110. 
Wagner, Max Leopold. "El supuesto andalucismo de América y la teoría climatológica”, Revista de Filología Española 14 (1927): 20-32. 